\title{
RELAÇÃO ENTRE A PRODUÇÃ̃ DE HSP60 POR CÉLULAS MONONUCLEARES DO SANGUE PERIFÉRICO DE PORTADORES DE PERIODONTITE E OS NÍVEIS DE SANGRAMENTO À SONDAGEM.
}

\section{Liliane Brito de Oliveira ${ }^{1}$; Soraya Castro Trindade ${ }^{2}$; Paulo Cirino de Carvalho Filho $^{3}$; Ana Carla Montino Pimentel ${ }^{4}$ e Márcia Tosta Xavier ${ }^{5}$}

\author{
1. Estágiária do PEVIC, Graduanda de Odontologia, Universidade Estadual de Feira de \\ Santana, e-mail: lilianeboliveira@ outlook.com \\ 2. Orientadora, Departamento Saúde, Universidade Estadual de Feira de Santana, \\ e-mail: soraya.castrotrindade@gmail.com \\ 3. Co-autor, Programa de Pós-Graduação em Imunologia, Universidade Federal da Bahia, email: \\ pauloccf@yahoo.com \\ 4. Co-autor, Programa de Pós-Graduação em Imunologia, Universidade Federal da Bahia, \\ email:anacpimentel_ba@hotmail.com \\ 5. Co-autor, Escola Bahiana de Medicina e Saúde Pública, \\ email: tostamarcia@gmail.com
}

PALAVRAS-CHAVE: Periodontite; HSP60; Porphyromonas gingivalis .

\section{INTRODUÇÃO}

A periodontite é uma doença infecciosa geradora de condições inflamatórias, que resultam na destruição dos tecidos de sustentação dos dentes (osso, ligamento periodontal e cemento) (VAN DYKE \& SERHAN, 2003). Clinicamente é caracterizada pela perda de tecido conjuntivo de inserção ao dente na presença de inflamação gengival. Associada à perda de inserção há a migração do epitélio juncional e oral ao longo da superfície dentária e reabsorção óssea (ARMITAGE, 1999). A gengiva apresenta-se edemaciada, exibindo alterações de cor, que varia do vermelho-pálido até magenta, sangramento espontâneo ou como resposta à sondagem periodontal. Pode ser encontrado exsudato inflamatório relacionado ao fluido gengival e supuração da bolsa. As profundidades das bolsas podem variar e as perdas ósseas podem ser horizontais e verticais, podendo levar a mobilidade dental nos casos mais avançados (CARRANZA et al., 2004).

Diversas moléculas podem estar envolvidas na patogênese da periodontite. Dentre elas, podem ser citadas as HSPs, que fazem parte de um grupo chamado "chaperonas moleculares". Elas recebem este nome por acompanharem, em condições metabólicas normais, proteínas desdobradas e polipeptídeos durante o seu transporte celular, permitindo que estas moléculas passem através de membranas e que sejam inseridas dentro de organelas celulares. (CHANDRA et al., 2007). Essas proteínas estão entre as mais conservadas e imunogênicas compartilhadas entre eucariotos e procariotos. Em condições fisiológicas, são responsáveis pela manutenção da integridade e função de outras proteínas celulares quando as células são expostas a estímulos estressores, tais como hipóxia, isquemia, hiperoxia, anoxia, deficiência nutricional, infecção, exposição a carcinógenos, entre outros (KAUFMANN, 1990).

Devido a sua alta conservação entre patógenos microbianos e sua capacidade de induzir resposta imune celular e humoral, HSP60 tem sido sugerida como possível candidato antigênico na periodontite. Foi demonstrado que HSP60 humano pode ser alvo de respostas autoimunes na periodontite devido ao mimetismo molecular com a homóloga GroEL de Porphyromonas gingivalis (YAMAZAKI et al., 2002). E segundo 
Pimentel (2014), as células mononucleares de sangue periférico (CMSP) extraídas de humanos que não possuem periodontite apresentam níveis de HSP60 mais elevados que aquelas extraídas de portadores de periodontite crônica, levantando também a possibilidade da expressão de HSP60 na célula humana exercer um papel protetor contra a periodontite.

Diante do exposto, torna-se relevante uma investigação sobre a relação entre a produção de HSP60 em portadores de periodontite e os níveis de sangramento à sondagem.

\section{METODOLOGIA}

Os participantes do estudo foram examinados de acordo com os descritores clínicos periodontais e aqueles que apresentaram 4 ou mais dentes com um ou mais sítios com profundidade de sondagem maior ou igual a $4 \mathrm{~mm}$, com perda de inserção clínica maior ou igual a $3 \mathrm{~mm}$ no mesmo sítio e presença de sangramento ao estímulo compõe o grupo teste (GOMES FILHO et al. 2007).

\section{COLETA DE SANGUE}

O sangue coletado foi diluído em salina tamponada com fosfato (STF), aplicado a uma camada de FICOLL e submetido a centrifugação. $\mathrm{O}$ anel de interface enriquecido de células mononucleares de sangue periférico foi coletado, lavado e ressuspenso em meio de cultura Roswell Park Memorial Institute (RMPI), e passou para contagem em contador de células (CELM).

\section{CULTURA DE CÉLULAS}

As células mononucleares do sangue periférico (CMSP), separadas na etapa anterior, foram cultivadas com antígenos de Porphyromonas gingivalis por $48 \mathrm{~h}$. A lectina POKWEED (PWM) foi utilizada como controle positivo. Para controle negativo, as CMSP também foram cultivadas apenas com o meio de cultura.

\section{ENSAIO IMUNOENZIMÁTICO (ELISA) PARA DETECÇÃO DO HSP60}

As concentrações de HSP60 nos sobrenadantes das culturas de células foram mensuradas usando-se kits disponíveis comercialmente (R\&D Systems, Inc., Minneapolis, USA). Os ensaios foram realizados usando-se placas de poliestireno de alta adsorção com 96 poços de fundo chato (SKC-109A - Anti-HSP60, Immunoassay Plate). As amostras foram diluídas conforme padronização prévia em diluente de reagente bem como todas as demais etapas foram realizadas de acordo com as instruções do fabricante. A densidade ótica foi determinada em Leitora de ELISA (ELx 800 - Bio-Tek) ajustada para um comprimento de onda na faixa de $450 \mathrm{~nm}$.

\section{RESULTADOS E DISCUSSÃO}

Participaram do estudo 27 voluntários, 11 no grupo com periodontite crônica (PC), e 16 no grupo sem periodontite (SP). Entre os participantes do grupo CP, 7 $(63,6 \%)$ eram do sexo feminino e $4(36,4 \%)$ eram do sexo masculino. Já no grupo SP, 9 $(56,3 \%)$ eram do sexo feminino e $7(43,7 \%)$ do sexo masculino. A média de idade dos participantes do grupo PC foi de 39,8 anos $\pm 7,5$ anos, com limite mínimo de 25 anos e máximo de 48 anos. Já a média de idade das participantes do SP foi de 38 anos $\pm 11,5$ anos, com limites mínimo e máximo de 20 anos e 57 anos, respectivamente. Os grupos PC e SP demonstraram homogeneidade entre si com relação a estas duas características, 
já que não foram observadas diferenças estatisticamente significantes na média da idade ( $\mathrm{p}=0,650$; Mann-Whitney) e na proporção de indivíduos do sexo masculino ou feminino ( $\mathrm{p}=0,701 ;$ Qui-quadrado).

O grupo $\mathbf{P C}$ apresentou um percentual médio de sítios com sangramento à sondagem de 29,9 enquanto que o valor para o grupo SP foi de 8,6 ( $\mathrm{p}=0,002)$. Entretanto, não foi observada correlação entre o percentual médio de sítios com sangramento à sondagem nos indivíduos com periodontite e os níveis de HSP60 produzidos pelas CMSP, independentemente da condição de cultivo empregada: sem estímulo, estimuladas com PWM e estimuladas com HSP60.

\section{Correlação entre os níveis de HSP60 induzidos por HmuY e o percentual de sítios com sangramento à sondagem}

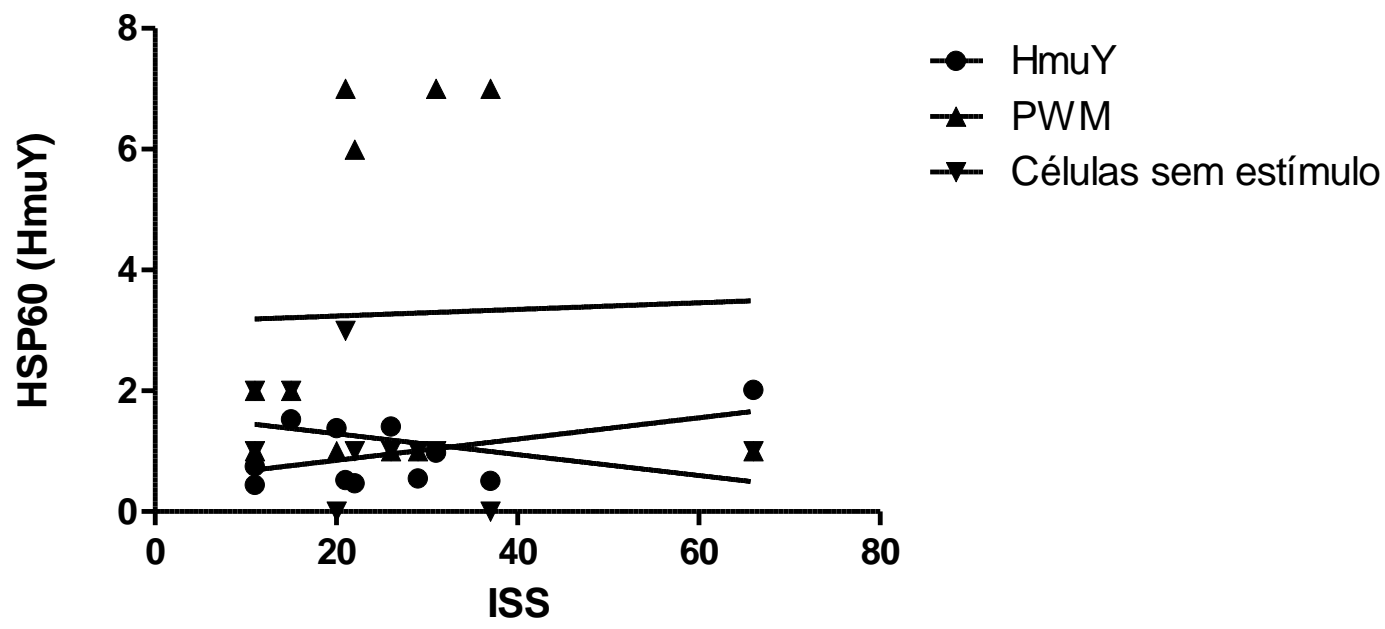

A proteína HmuY tem se mostrado importante na patogênese da periodontite, atuando na resposta imune induzindo a produção de citocinas, como IL-10, IL-1 $\beta$ (TRINDADE et al., 2012a) e IL-6 (TRINDADE et al., 2013), além de inibir a expressão de proteínas anti-apoptóticas, como BCL-2. (CARVALHO-FILHO et al., 2013). Por outro lado, estudo do papel de uma HSP60 humana na patogênese da periodontite é escasso e a análise de correlação entre a produção desta proteína induzida por rHmuY e a condição periodontal é inédita.

Apenas um estudo (PIMENTEL, 2014) sobre a produção de HSP60 induzida por rHmuY encontrado na literatura demonstrou que os níveis basais desta proteína de choque térmico são mais elevados em indivíduos sem periodontite. Quando as células destes indivíduos são estimuladas por 48h com rHMUY, estes níveis são drasticamente reduzidos. Já nos portadores de periodontite, estes níveis basais já se encontram em níveis inferiores em relação aos clinicamente saudáveis, mas ainda assim reduzem após estímulo com rHmuY.

Entretanto, não foi possível observar uma correlação entre o percentual de sítios com sangramento à sondagem e a produção de HSP60. É possível que o tamanho da amostra tenha afetado o poder da análise. Visto que, pelo racional de que as nuances de gravidade clínica relacionadas ao sangramento só poderiam ser observadas no grupo de indivíduos com a doença, apenas os dados destes indivíduos entraram na análise de correlação. 
Embora ainda preliminares, os achados do presente estudo demonstram relevância clínica, uma vez que as proteínas de choque térmico, em particular HSP60, têm sido apontadas como alvos terapêuticos em razão da sua função de reparo celular. Sendo assim, a continuidade da pesquisa será de grande importância para elucidar o papel de HSP60 na patogênese da periodontite.

\section{CONCLUSÃO}

Diante do método empregado e das limitações do estudo, foi possível concluir que os níveis de sangramento à sondagem não estão correlacionados à produção de HSP60 células de indivíduos portadores de periodontite.

\section{REFERÊNCIAS:}

VAN DYKE TE \& SERHAN CN. Resolution of inflamation: a new paradigma for the Pathogenesis of Periodontal Diseases. J. DENT Res, vol.82, n. 82, 2003.ARMITAGE G. The pathogenesis of periodontial diseases. J periodontal, vol. 70, p. 457-470, 1999.

CARRANZA F.A.; NEWMAN, M.G.; TAKEY,H.H. Periodontia Clínica. Guanabara Koogan, 9a ed., 2004.

CHANDRA D, CHOY G \& TANG DG Cytosolic Accumulation of HSP 60 during apoptosis with or without Apparent Mitochondrial Release: Evidence that its proapoptotic or pro-survival functions involve differential interactions with caspase-3. J. Biol. Chem., vol. 282, p.31289-31301, 2007.CHOI $J$ et al. Identification of ummunoreactive epitopes of the Porphyromonas gingivalis heat shock protein in periodontitis and atherosclerosis. Journal of Periodontal Reasearch. V. 46, n. 2, p. 240245, april, 2011.

KAUFMANN SHE. Heat Shock Proteins and Immune Response. Immunology Today, Vol. 11, p. 129-136,1991.

YAMAZAKI K et al. Accumulation of Human Heat Shock Protein 60-Reactive T Cells in the Gingival Tissues of Periodontitis Patients. Infect. Immun., vol. 70, n.5, 2002.

CARVALHO-FILHO et al. Porphyromonas gingivalis HmuY stimulates expression of Bcl-2 and Fas by human CD3+ T cells. BMC Microbiology, vol. 13, n. 206, 2013.

GOMES-FILHO IS et al. Exposure measurement in the association between periodontal disease and prematurity low birth weight. J periodontol, v. 34, p.957963, 2007

PIMENTEL, acm. O papel de hmuy de porphyromonas gingivalis na produção de hsp60 por células mononucleares do sangue periférico de portadores de periodontite crônica. Universidade Federal Do Estado Da Bahia. Salvador - Bahia;2014; Dissertação Do Mestrado.

TRINDADE et al, Induction of interleukin (IL) - I $\beta$, IL-10, IL-8 and Imunoglobulin G by Porphyromonas gingivalis HmuY in humans. J Periodont Res vol.47, p. 27-32, 2012a.

TRINDADE et al., Porphyromonas gingivalis Hmuy - Induced Production of Interleukin-6 and IL-6 Polymorphism in Chronic Periodontitis. J Periodontal, vol. 84, p. 650-655, 2013. 